\title{
Família, terra e trabalho: modos de vida nos cafezais de montanha do sul de Minas Gerais
}

Family, land and labor: ways of living in the mountain coffee plantations in south of Minas Gerais

\author{
Celso Antônio Spagggiari Souza* \\ Rita de Cássia Santos Freitas**
}

\begin{abstract}
Resumo:
Este texto tenta compreender a mobilidade social e econômica de pequenos cafeicultores das regiões montanhosas do Sul de Minas Gerais, elegendo como fio condutor das análises as fortes imbricações nas suas vivências entre família, terra e trabalho. Utilizando a força do trabalho familiar, munidos do conhecimento adquirido nas lidas permanentes com a lavoura de café, nas suas relações com a comunidade e nos serviços de extensão rural, esses sujeitos conseguiram superar a condição original de escassez de recursos econômicos e angariar algum patrimônio, ampliar suas condições de vida e serem reconhecidos no seu grupo social. Para tanto, faz-se uso da observação participante, o acolhimento de histórias de vida de três agricultores em diferentes municípios dessa região, indicadores do último censo agropecuário e o apoio em autores que se dedicam ao tema em uma epistemologia antropológica.
\end{abstract}

Palavras-chave: Trabalho rural; Família rural; Terra e trabalho; Cafeicultura de montanha; Cafeicultores familiares.

\begin{abstract}
:
This text tries to understand the social and economic mobility of small coffee producers of the mountainous regions of Southern Minas Gerais, choosing as a guide analyzes the strong overlapping of family, land and labor in their life experiences. Using the strength of family labor, armed with the knowledge acquired in the permanent toils with the coffee crop, in the relations with the community and services of rural extension, these social actors managed to overcome the original condition of lack of economic resources and raise some patrimony, expand their living conditions and be recognized in their social group. To this end, we make use of the participating observation, the host of life stories of three farmers in different municipalities of the region, indicators Agriculture Census and support of authors who are dedicated to the subject in an anthropological epistemology.
\end{abstract}

Key words: Rural labor; Rural family; Rural labor; Rural family; Land and labor; Mountain coffee plantations; Coffee family farmers.

\footnotetext{
*Universidade Federal Fluminense. Professor do Instituto Federal de Educação, Ciência e Tecnologia do Sul de Minas Gerais - Campus Muzambinho. Mestre em Política Social e Doutorando em Política Social pela Universidade Federal Fluminense. E-mail: celsospaggiari@gmail.com

** Universidade Federal Fluminense. Professora da Escola de Serviço Social da Universidade Federal Fluminense-Pós-Doutora Centro de Estudos Sociais Universidade de Coimbra-Portugal. E-mail: ritacsfreitas@uol.com.br
} 


\section{Introdução}

O trabalho nas plantações de café no sul de Minas Gerais é uma das ocupações mais longevas e ininterruptas da economia rural desta região do estado. Das muitas faces que a cafeicultura mineira expressa, a que tem se mantido mais persistente é a de ser, por enquanto, a mais intensiva empregadora de trabalhadores no campo. Para viabilizar essa lavoura, durante sua longa trajetória, já foram utilizados, intensamente, a mão de obra escrava, o trabalhador livre nacional, os colonos migrantes e os nacionais, parceiros, arrendatários, meeiros e o trabalhador assalariado. E nos últimos tempos, seguindo "a tendência geral da produção capitalista em todos os ramos produtivos", os processos mecanizados na lavoura de café, ainda que parcialmente, têm tomado o lugar do "trabalho vivo"; o trabalho humano vai sendo substituído pela máquina, confirmando a previsão que fizera Marx (1994), já em 1863, ainda que, aqui, em ritmo mais lento e tardio que em outros processos produtivos.

Deve-se reconhecer que as profundas transformações capitalistas nos modos de produzir das últimas décadas estão entrelaçadas com a dinâmica atual da agricultura que se moderniza, racionalizando todas as etapas da produção, reconfigurando sua força de trabalho, e parece, ainda, postular no contraponto urbano um ideal civilizatório a ser atingido (VEIGA, 2007). Ainda que o capitalismo mais abrangente tenha chegado mais tardio ao campo, ele continua seguindo inexorável sua trajetória, atinge todos os rincões do país com forças homogeneizadoras sobre a cultura rural, parecendo validar "a grande narrativa de dominação ocidental", no dizer de Sahlins (1997, p. 15).

No entanto, longe de se tomar esse território homogêneo e ordenado em um espaço único, uma análise mais acurada demonstra que do campo emergem diversos arranjos da produção, em diferentes condições ambientais, econômicas e sociais, validando e fortalecendo, em muitos casos, culturas locais, em vez de suprimi-las. Assume-se a recusa às explicações mecanicistas dos comportamentos dos sujeitos sociais (REVEL, 1998). É o que anima este trabalho: tenta-se acompanhar a história de três famílias de trabalhadores de café que vivenciaram as experiências de colonos, trabalhadores assalariados, meeiros e proprietários. Foram essas ocupações que, ao longo de suas vidas, garantiram a reprodução social, a emancipação econômica e o reconhecimento de tais sujeitos nas suas comunidades. Busca-se nos seus rastros, nas suas falas e com um pouco de convivência 
com esses sujeitos alguma ordenação para esta trama. Que orientações e sentidos esses sujeitos imprimiram às suas vidas e de suas famílias que permitiram a superação de condições originais de existência tão precárias? Quais estratégias estabeleceram e que desafios tiveram que enfrentar? Como se relacionaram com as políticas públicas que afetam suas atividades?

Deve-se reconhecer que esses "relatos de sucesso" constituem minorias. Boa parte dos trabalhadores do café continua mesmo é vendendo sua força de trabalho no mercado com esperanças de mera sobrevivência.

Porque a pesquisa foca em elementos do cotidiano, modos de vida, organização e funcionamento familiar, ética do trabalho e valores, relações de gênero na família e universo da cultura rural, utilizou-se da observação participante e histórias de vidas relatadas por membros das três famílias estudadas. Sem se demitir de certo afastamento necessário à análise geral, priorizou-se neste estudo o envolvimento direto nas condições dos sujeitos pesquisados - a "experience-nearcontraposta à experience-distant" - na proposição feita por Geertz (2008). Tentou-se, numa postura etnográfica, praticar "o olhar de perto e de dentro capaz de identificar, descrever e refletir sobre aspectos excluídos daqueles enfoques de fora e de longe", para utilizar as metáforas de Magnani (2002, p, 7). Estes últimos, em abordagens macro e quantitativas, apoiados nas abundantes informações quantitativas disponíveis em estatísticas oficiais e privadas, constituem recorrentes estudos rurais hoje em dia.

O estudo foi realizado no período de julho de 2012 a fevereiro de 2015, nos municípios de Jacuí e Guaranésia, ambos situados na mesorregião Sul de Minas Gerais. Nesse período, foi possível observar, acompanhar e, muitas vezes, participar com os sujeitos pesquisados em tarefas na lavoura de café, nos terreiros de secagem dos grãos, nas estruturas de benefício e armazenamento, discutir técnicas de produção e manejo dos cafezais, estender conversas informais nos finais de tarde ao fim de algum trabalho e ainda fazer parte de alguns eventos comemorativos com as famílias. Tentando-se a aproximação do enunciado de Geertz (2008, p. 22): “[...] um antropólogo não estuda as aldeias, ele estuda nas aldeias".

Com recorte bem delimitado - foram acompanhadas apenas três famílias de agricultores-cafeicultores -, a pesquisa possibilita identificar estratégias e desafios de 
trabalho, modos de organização familiar e de vidas, conflitos, crenças e valores que sustentam as hipóteses do poder descritivo e explicativo desses arranjos na emancipação econômica e social de alguns produtores e o "fracasso de outros tantos", no dizer deles mesmo.

Ainda que o recorte escolhido constitua uma totalidade empiricamente delineada, “[...] esta realidade arbitrária contém os elementos reconhecíveis como padrões, pode ser descrita, formalizada, constituindo um modelo mais geral. Aponta para uma lógica que transcende o contexto original, com poder descritivo e explicativo" (MAGNANI, 2002, p. 15), sem que isso constitua tentação que encaminhe para a busca de leis universais de caráter generalizante sobre esta cultura, como a epistemologia de uma ciência positiva.

Nas seções que se seguem, descrevem-se e interpretam-se os espaços, os feitos e os relatos de vida desses sujeitos, expondo suas idiossincrasias, e apresentam-se algumas possíveis conclusões.

\title{
A lavoura de café no sul de Minas: sobrevivência e reprodução social do produtor e da plantação
}

\begin{abstract}
Em toda conjuntura [...] podem-se observar duas categorias principais de fatos: os de persistência e os de alteração. Os primeiros constituem aquela parte do equipamento cultural e das formas sociais que, oriundos do período anterior, perduram no presente, estabelecendo continuidade entre as [...] etapas do processo de transformação. Os segundos são forças novas, geradas no seio do grupo, ou nele incorporadas [...] para reajuste do seu funcionamento (CÂNDIDO, 2010, p. 186)
\end{abstract}

Não obstante o avanço da cafeicultura empresarial de maior escala no Brasil, em Minas Gerais, plantar café ainda é uma atividade de pequenos e médios produtores. Isso evidencia uma característica da produção de café: por demandar muita mão de obra, pode ser exercida com certa vantagem comparativa por produtores familiares. Na mão deles estão $41,42 \%$ da área plantada no Brasil e $37,5 \%$ da produção, o que demonstra que alcançam produtividade média semelhante aos demais produtores (IBGE, 2009). Nos municípios de Guaranésia e Jacuí, municípios do estudo, a agricultura familiar na cafeicultura representa $85 \%$ dos produtores. Em um município vizinho, Nova Resende, os cafeicultores familiares representam $98 \%$ do total (IBGE, 2009). Contudo, a constatação 
desses números não deve esconder o conflito: os produtores de café com estabelecimentos até 20 ha perfazem 83,29\% do total em Minas e 83,06\% no Brasil, no entanto, ocupam $31,42 \%$ das terras (IBGE, 2009). Quando um produtor consegue comprar alguma terra, caso dos três cafeicultores deste estudo, sentem-se de fato vitoriosos. As terras do café (e todas as outras) continuam concentradas nas mãos de poucas pessoas. "Eu e minha mulher herdamos 0,5 alqueire de terra, hoje temos 18" (Conta orgulhoso José, 38 anos, agricultor cafeicultor familiar) ${ }^{1}$. "Eu comecei sem terra nenhuma e hoje nós temos 5 sítios, todos com café" (Pedro, 58 anos, agricultor-cafeicultor familiar)2.

O fato de a mão de obra ser muito relevante no custo de produção (40 a 70\%) e de os ganhos de escala com a mecanização serem reduzidos devem estar viabilizando a cafeicultura familiar e dando sobrevida à atividade cafeeira nos momentos mais desfavoráveis do mercado (SOUZA, 2012). Os preços do café são balizados pela Bolsa de Nova York, onde são negociados os contratos futuros com a presença dominante de fundos de investimentos especuladores - players financeiros globais -, conferindo ao mercado de café a maior volatilidade de preços entre todas as outras commodities agrícolas. O que confere enorme preocupação e riscos de comercialização para os produtores.

Essas regiões são tradicionais no cultivo de café desde o século XIX. No entanto, a capacidade de renovação e a adoção de tecnologias mais modernas e sustentáveis que elas têm apresentado devem explicar, em parte, a longevidade da atividade cafeeira em tais áreas. O relevo acidentado dificulta a substituição da cultura do café por outras mais passíveis de mecanização, o que, em parte, pode também explicar a permanência da cultura nessas regiões. "Aqui só planta café, o resto é muito pouco, só mesmo pro gasto" (José). O custo de oportunidade da terra é baixo - a possibilidade de uso da terra com outras culturas comerciais é restrita - e acrescido do envolvimento cultural desses produtores com a lavoura de café, transmitido por gerações, tem viabilizado a continuidade das plantações.

Algumas razões são frequentemente explicitadas para tentar explicar a sobrevivência da agricultura familiar: i) eficiência técnica de algumas produções familiares, como é o caso do café; ii) capilaridade e abrangência de políticas públicas mais recentes, principalmente

\footnotetext{
${ }^{1}$ A partir deste ponto do texto, será anotado apenas como José.

${ }^{2}$ A partir deste ponto do texto, será anotado apenas como Pedro.
} 
flexibilidade e resistência dos produtores que permitem adaptações e acomodações tecnológico-econômicas; iv) resiliência da produção familiar para aceitar baixos retornos sobre capital e trabalho; v) capacidade de funcionamento por estratégias não monetárias (como para autoconsumo e não pagamento de salários, por exemplo); vi) envolvimento e comprometimento dos trabalhadores familiares nos trabalhos como participantes legítimos nas decisões e definidores de suas vidas; vii) os membros familiares podem subsidiar a atividade trabalhando fora dela na esperança de tempos melhores (que foi encontrado nas três famílias desta pesquisa); viii) residência na propriedade dos responsáveis pelo seu gerenciamento e monitoramento (GRAZIANO DA SILVA, 1982; GUANZIROLI et al., 2009; MARTIN, 2008; STOLCKE, 1986).

Muitas dessas razões aparecem, espontânea e pedagogicamente, nas falas dos produtores:

\begin{abstract}
A gente cuida bem das lavouras. Café tem que cuidar direito. Meu pai não cuidava direito. Isso ele não me ensinou, ensinou a trabalhar, mas ele não adubava, não pulverizava, não punha calcário, não podava, cuidava no sistema antigo. Nós fazemos tudo que precisa. Café tem que cuidar senão não dá nada. A gente gasta com ele e ele agradece e dá muito mais de volta. Pode demorar, mas dá. Aprendi isso na Fazenda do Nenzito e com os agrônomos da cooperativa (a fazenda em que ele morou e a Cooperativa em que é associado). Hoje tem doença que não tinha antigamente, tem mais praga, se cuidar no sistema antigo não produz. Tudo que nós temos, eu devo ao café (Pedro).
\end{abstract}

Nós sempre moramos aqui na roça mesmo. Meu pai também morou a vida inteira na roça. Além do café tem umas criações e a gente planta algumas coisinhas pro gasto. É pouco mais dá pro gasto. Tem galinha, vaca de leite, milho e feijão, mandioca e sempre tem alguma verdura e fruta. A gente que cuida de tudo, eu, a mulher, os dois meninos e um cunhado (José).

Eu e meu irmão fazemos Pronaf todo ano, a gente paga em dia pra poder pegar o dinheiro todo ano. Ajuda muito, o juro é barato e pode pagar com a colheita do café. Melhorou muito depois disso. Antes a gente não pegava financiamento no banco. Era tudo por conta da gente mesmo e era mais difícil (Antônio, 35 anos agricultor-cafeicultor) ${ }^{3}$.

O envolvimento com a atividade cafeeira nessa região tem sobrevivido às gerações desses agricultores. Faz parte do aparato cultural dos mais velhos que vão transmitindo aos mais jovens o conhecimento e o gosto pela atividade. Por se tratar de atividade de intensiva

\footnotetext{
${ }^{3}$ A partir deste ponto do texto, será anotado apenas como Antônio.
} 
dinâmica de trabalho e técnicas que envolvem os produtores em todas épocas do ano com os plantios, tratos da lavoura, podas, adubações, colheita, comercialização, confere dinamismo à vida diária das pessoas envolvidas.

É uma atividade antiga - os primeiros plantios da região, segundo Souza (2012), datam de 1835 -, mas, por estar fortemente integrada aos mercados, renova-se continuamente nas técnicas de produção, processos, máquinas, equipamentos, o que permite a atração e o envolvimento dos filhos jovens desses produtores, geralmente de espírito mais inovador. Aparece de forma sintomática na fala de José: “Um filho forma já agora neste ano [ensino médio] e vai ajudar direto na lavoura, porque já temos muito café pra nós cuidar, e ele não precisa procurar emprego fora". Se a decisão do pai - e também do filho - de interromper os estudos ao fim da educação básica indica menor ênfase na formação escolar que no trabalho, não deixa de indicar também o espírito empreendedor desses personagens. E, afinal, José tem 4 anos de estudo, a esposa tem 8 e o filho completará 11 anos de escolaridade. Não deixa de ser um avanço.

\section{O trabalho, a família e a terra como modos de vida}

\section{A Vida Estruturada sob a Ética do Trabalho Familiar Intenso}

Nas observações seguidamente feitas e na fala dos entrevistados, a crença no sobreesforço e no trabalho coletivo da família se repete seguidamente, sempre manifesta na vontade de progredir. Mas o que dizer das outras 19 famílias que moram até hoje na mesma propriedade em que Pedro morou e que não conseguiram romper com a situação?

Uma pesquisa que lidasse apenas quantitativamente com a questão captaria a situação de opressão desses trabalhadores, mas dificilmente daria relevo à situação singular do progresso dos entrevistados. A macro-história tem concluído: as relações capitalistas proletarizaram os trabalhadores rurais. Na microanálise: a percepção da realidade é mais complexa, consegue captar as contradições, os trabalhadores rurais assalariados podem, em condições específicas, tornar-se pequenos agricultores familiares e viver em melhores condições de vida. Senão, como explicar a predominância e a sobrevivência de pequenos e médios produtores de café no sistema fundiário dessa região? Talvez as narrativas do entrevistado deem as pistas. 
Por visão macro, parece um milagre a descoberta oficial, razoavelmente recente, deste universo de pequenos produtores, enquanto os indicativos são de uma existência antiga e persistente, diz a história de vida do produtor. A seguir, alguns excertos do discurso de Pedro que autorizam essa leitura:

Agora, o primeiro pé-de-meia que nós fizemos foi quando os irmãos e eu pegamos uns café pra tocar a meia na fazenda. Aí nós trabalhamos muito. Não tinha tardinha, domingo e feriado, era muito serviço, tudo fora do horário da fazenda, e deu certo [...]

Se trabalhar firme e direitinho, igual nós trabalhamos, a gente consegue as coisas também. Nós estamos acostumados trabalhar de sol a sol. A gente sabe que sempre foi assim.

Se eu continuasse trabalhando só no salário, não tinha o que tenho hoje, porque aí trabalha menos, mas ganha menos.

Nós trabalhamos muito depois do horário de serviço [...] porque gosta de cuidar da lavoura e têm vontade de progredir...

O entrevistado tem um discurso que se repete na pessoa do plural, ele insiste que o seu progresso de vida se deu pela ação conjunta com seus familiares. Seu discurso raramente aparece na primeira pessoa. O foco é o "nós" e o "a gente". A referência à família ou aos membros dela é constante no texto. Isso fica ainda mais claro nesta fala do entrevistado:

Eu peço a Deus que dê saúde para nós continuarmos e para os filhos aumentar o pé de meia deles porque eles também gostam da roça.

A gente trabalha junto, todo mundo, até a mulher tem ido para a roça [...].

Quando aperta o serviço e ele não dá conta, a gente faz um mutirão e ajuda ele.

Agora, o primeiro pé-de-meia que nós fizemos foi quando os irmãos e eu pegamos uns café pra tocar a meia na fazenda.

As relações tradicionais de exploração do trabalho rural que condenam a maioria desses trabalhadores à condição de simples reprodução e sobrevivência podem ser rompidas, em condições singulares, mas com muita frequência. As sobredeterminações econômicas que geram a exclusão também podem permitir a inclusão, essa ambivalência pode ser explicitada na história de vida dos agricultores deste estudo. 


\section{A família que se Estende para Fora da Casa}

O sentimento de família compreende a casa com os frequentadores diários levados à intensa movimentação, quase sempre associada às tarefas desempenhadas de forma coletiva, geralmente as da lavoura principal, que é o café. E as tarefas da casa, do cuidado com animais e outras plantas que não o café e demais atividades de subsistência, apresentam-se com algum grau de divisão do trabalho, por gênero e por geração. As mulheres e as crianças maiores cuidam mais da casa e das plantações anexas, como as flores rústicas que enfeitam as proximidades da moradia (que exigem cuidados diários menos intensivos), as frutas e as hortaliças de consumo doméstico (também as mais rústicas), e dos pequenos animais (galinhas e porcos, em dois casos). Já os homens cuidam dos trabalhos com os grandes animais (nos três casos, vacas de leite) e das plantações de subsistência mais distante, como o milho e o feijão.

Nós trabalhamos muito. Não tem dia nem hora. Somos dois cunhados e dois sobrinhos trabalhando juntos também, além do meu irmão. Então, todo mundo quer ir para frente. É fazer para melhorar sempre. Na roça é no mutirão mesmo. Em casa também cada um faz sua parte (Pedro).

Deve-se compreender o conceito de família estendida, abrangendo, além de filhos e filhas, outros parentes mais distantes, ou mesmo pessoas fora do grau de parentesco, mas que compartilham as preocupações e as responsabilidades inerentes à reprodução social e econômica do grupo. Há um líder, um cabeça, na fala deles próprios. Nos três casos do estudo, o homem é o responsável pela família que exerce conjuntamente com a mulher uma liderança moderada e aglutinadora, mais democrática (segundo a leitura de um entrevistado), atendendo aos interesses do grupo de forma individualizada, mas sem perder o controle do interesse coletivo, o que faz das suas famílias espaços privilegiados de consumo controlado e de produção com viés de poupança.

Esse controle parece constituir, no entender deles, a condição necessária para serem bem-sucedidos. Dois desses produtores vendem as suas produções parceladamente ao longo do ano, com o consentimento e a participação das suas mulheres nas decisões. Eles acham natural e necessária tal participação: "Se errar na venda, a gente erra junto ou acerta junto" (José); "A Nicinha discute a venda comigo porque é a etapa mais difícil do café. Produzir a gente sabe, vender na hora certa é mais difícil" (Antônio). 
Colabora com essa constatação o estudo de Faria (1997, p. 256), “História da Família e da Demografia Histórica":

Foi da ou para a família, não necessariamente a consanguínea, que todos os aspectos da vida cotidiana, pública ou privada, se originaram ou se convergiram. A família conferia aos homens estabilidade ou movimento [...]. Pouco se referia ao indivíduo enquanto figura isolada sua identificação era sempre com um grupo mais amplo. O termo "família" apareceu sempre ligado a elementos que extrapolavam os limites da consanguinidade, entremeava-se à coabitação [...].

A família de Pedro trabalha na lavoura de café durante a colheita com 20 pessoas, todas com algum grau de parentesco. $\mathrm{Na}$ época dos tratos culturais dos cafezais (épocas de tarefas de menor dispêndio de mão de obra), esse contingente ocupa-se em outras lavouras, na maioria dos casos, deles próprios, "cada um tem um pedaço de café para tocar" em pequenas propriedades deles ou de terceiros. Situações semelhantes ocorrem nas famílias de Antônio, em que 7 pessoas se revezam entre os trabalhos dele e os próprios, e na de José, 5 pessoas. Em qualquer situação inusitada de algum "aperto de serviço", o grupo está apto a se juntar "em mutirão para salvar o apertado". Embora utilizem a expressão mutirão, ela tem outro significado para eles. Todo trabalho é remunerado, não é favor que se presta. Segundo o dicionário Aurélio (FERREIRA, 1986, p. 958),

Mutirão é o auxílio gratuito que prestam uns aos outros os lavradores, reunindose todos os da redondeza e realizando o trabalho em proveito de um só, que é o beneficiado, mas que neste dia faz as despesas de uma festa ou função. Este trabalho pode ser a colheita, ou queima, ou roçado, ou plantio [...].

O mutirão deles é uma atualização remunerada da prática de ajuda mútua, prevalecendo o compromisso da solidariedade e o pronto atendimento de qualquer membro do grupo no momento em que ele mais demanda o serviço.

Em “Herança e gênero entre agricultores familiares", Carneiro (2001, p. 27) também detecta uma atualização do significado do trabalho para as gerações mais novas dentro das famílias:

O trabalho [...] que constitui a categoria cultural central do universo das primeiras gerações de colonos, também adquire uma nova significação; deixa de ser a expressão de um valor moral, e passa a ser encarado como tão-somente um meio de realização pessoal. 
O trabalho continua representando um valor cultural estruturante para a vidas desses agricultores, eles se sentem compromissados a trabalhar para o grupo, mas a remuneração pelos serviços executados passa a ser uma norma nas relações entre eles.

\section{A Terra como Espaço de Produção do que Comer e da Esperança de Progredir}

A vida na roça emerge na narrativa do entrevistado como modo de vida, trabalhar na roça é para ele modo de produção da vida, um pertencimento cultural, uma forma ética de existir, forma de produzir a subsistência material e simbólica. Os valores familiares, o sobre-esforço, a capacidade de trabalho coletivo e solidário e o conhecimento adquirido na vida são os ingredientes de sucesso na visão do entrevistado, mesmo que isso não seja nomeado dessa forma por ele.

Os excertos seguintes do discurso dos entrevistados autorizam essa leitura:

Nossa turma é a mulher, eu, dois filhos, um cunhado e dois irmãos que sempre tá junto no serviço (José).

A nossa maior diversão é o serviço. A gente trabalha junto, todo mundo, até a mulher tem ido para a roça agora que não trem criança pequena (Pedro).

Nós nunca estamos sozinhos, nós ajudamos todo mundo aqui perto, somos respeitados nesse lugar, tem os amigos dos meninos, os amigos da gente, tenho um nome limpo, não tenho inimizade nenhuma, a casa está sempre cheia, e isso distrai a gente (Pedro).

A gente foi criado com pouco, às vezes tinha mal pra comer, e hoje tem fartura, progrediu, criou bem os filhos, tem saúde, por isso tem que agradecer a Deus, porque está bom demais (Antônio).

Para Almeida (2003, p. 75), as vidas desses sujeitos estão ordenadas em torno dos ciclos naturais do plantar e do colher, "[...] suas decisões são orientadas pelas necessidades do núcleo familiar". "Pra nós não pode faltar nada para quem trabalha, mas todo mundo tem que trabalhar muito pra isso" (José).

Em estudo sobre patriarcalismo, Família e Poder na Sociedade Brasileira (Séculos XVI$X I X)$, Samara (1991, p. 10) assim se expressa: “[...] era quase uma contingência para os indivíduos se incorporarem às famílias e grupos de parentesco, que funcionavam, ao mesmo tempo, como organizações defensivas e unidades econômicas". 
Em História da Família no Brasil Colonial, estudando as formas e as possibilidades de acesso à terra nesse período, Silva $(1998$, p. 87) afirma que a condição de "possuir família constituía o principal argumento para a concessão de terras".

E para Woortmann (1990, p. 37),

O sentido do campesinato e de seus sujeitos se encontra no significado da terra e da família como representação de sua vida, de sua moral, de seu trabalho. Terra e família são categorias centrais do discurso camponês e expressam uma relação moral entre os homens e deles com a natureza.

Estes agricultores familiares que cultivam cafezais em montanhas estão funcionalmente integrados ao mercado. Utilizam técnicas modernas de produção, insumos industriais, fazem uso dos serviços de assistência técnica e extensão rural públicos e privados, utilizam crédito rural, estão atentos às inovações produtivas, são filiados à cooperativa de produtores da região, comercializam seu produto em mercado futuro. Para nós, essa condição de inserção plena no mercado distancia esses sujeitos da categoria de camponês, embora vários traços da cultura camponesa estejam presentes nos seus modos de vida e reprodução social.

Estão preocupados com a segurança alimentar de seu grupo. Tem nos cafezais seu produto comercial, ao qual dedicam intensamente seu tempo de trabalho. No entanto, não abandonam as culturas e as criações alimentares básicas responsáveis pela "fartura" e pelo sustento de suas famílias. Sentem-se envergonhados quando, por alguma intempérie ou descuido, têm que comprar na cidade algum produto que deixaram de produzir. Viver em meio à fartura de alimentos produzidos por eles é motivo de grande satisfação para os participantes, principalmente para os mais velhos.

E isso é o que suas vidas conservam: esses valores saltam das suas falas e de suas crenças, emergem na organização dos seus trabalhos com a terra, nas relações com a família e com os outros. Parece que para produzir de forma econômica incorporaram-se ao mercado, sem abandonar os seus modos de vida mais tradicionais: "Os meus dois meninos (um tem 18; e outro, 22 anos!) tem moto, carro, tem de tudo, só não pode ter preguiça" (Pedro). "Nós trabalhamos para a família juntos, aqui não é cada um por si, nem depois de casado" (José). "Nós não temos propriedade para negociar, temos terra” (Antônio). 
Assim, é prudente afirmar: não existem nem tipos ideais nem sujeitos rurais puros. Procurar por eles no campo pode ser uma abstração inútil. As estruturas globais se generalizam nos modos de produção da vida material e nas consciências dos sujeitos, mas as forças locais sobrevivem e resistem em ser deslocadas.

\section{A terra e a Família Estruturam as Subjetividades}

As crenças do trabalhador são elementos determinantes da sua identidade cultural e lhe conferem a sensação de pertencimento e responsabilidade com sua comunidade. A pesquisa que utiliza a abordagem qualitativa, como a história de vida, possibilita a visibilidade desses valores, que não se mensuram numericamente. A história de vida é singular e é também coletiva. Na sua singularidade, as imbricações culturais se expressam porque os entrevistados pertencem a uma comunidade e à sua cultura.

Na sequência, alguns excertos do discurso dos entrevistados que autorizam essa leitura:

\footnotetext{
Nós nunca estamos sozinhos, nós ajudamos todo mundo aqui perto, somos respeitados nesse lugar, têm os amigos dos meninos, os amigos da gente, tenho um nome limpo, não tenho inimizade nenhuma, a casa está sempre cheia, e isso distrai a gente (Pedro).

A gente tem que agradecer a Deus por tudo que tem (José).

A gente foi criado com pouco, às vezes tinha mal pra comer e hoje tem fartura, progrediu, criou bem os filhos tem saúde, por isso tem que agradecer a Deus, porque está bom demais (Antônio).

Quando aperta o serviço e ele não dá conta, a gente faz um mutirão e ajuda ele (Pedro).

Aprendi cuidar direito da lavoura (Antônio).
}

Ao fazer considerações sobre a (re) criação do campesinato brasileiro nos movimentos sociais rurais, Martin (2008, p. 4) afirma: "A terra significa mais que uma propriedade, nela os sujeitos se encontram, constroem suas subjetividades; [...] no significado da terra e da família encontram a representação de sua vida, de sua moral, de seu trabalho".

Na voz de Antônio, outro entrevistado: 
Serviço pra nós é diversão. A gente trabalha junto, com satisfação no que faz. $E$ hoje o serviço não é difícil como antigamente, tem mais facilidade, tem trator, mais maquinário, condução para ir pra roça, carro para ir na cidade a hora que quer. Não depende mais dos outros para trabalhar não, precisa coisa melhor? Aqui em casa sempre tem gente. Nós nunca estamos sozinhos, nós ajudamos todo mundo aqui perto, somos respeitados nesse lugar, têm os amigos dos meninos, os amigos da gente, tenho um nome limpo, não tenho inimizade nenhuma, a casa está sempre cheia, e isso distrai a gente. A gente foi criado com pouco, às vezes tinha mal pra comer, e hoje tem fartura, progrediu, criou bem os filhos, tem saúde, por isso tem que agradecer a Deus, porque está bom demais [semblante de satisfação]. Festa que a gente gosta é da igreja e os casamentos que a gente costuma participar.

Em pesquisa semelhante, intitulada "A Casa, os sítios e as agrovilas: uma poética do tempo e do espaço no assentamento de trabalhadores rurais das Terras de Promissão-SP", D'Aquino (1996, p. 21) constata:

[...] A terra é o patrimônio de família, sobre a qual se faz o trabalho que constrói a família enquanto valor. São categorias culturais centrais do universo camponês brasileiro, o trabalho, a família e a liberdade. Pode-se opor esse tipo de sociedade às sociedades modernas, individualizadas e voltadas para o mercado, nas quais as três categorias estão separadas.

Coincidem para essas pessoas diversão e trabalho. Elas parecem gostar tanto do que fazem que lazer e trabalho se confundem. São acostumadas ao trabalho com a terra, incorporaram-no como a única forma de escaparem das extremas dificuldades materiais que vivenciaram ou thes rondaram em alguma fase da vida. Hoje, o trabalho intenso, coletivo, eficiente, na visão deles, faz parte de suas identidades. Acham-no mais fácil por terem incorporado equipamentos e técnicas que o tornaram mais ameno do que consideram ter sido no passado.

\section{Conclusão}

Pode-se escrever a história de um grupo restrito de indivíduos sem se esmaecer a visão generalizante do todo a que eles pertencem. Ao inverso, o desnudamento de outras realidades encobertas contribui para a compreensão de sentidos, nuances que abordagens macro de estudos totalizantes não permitiriam captar. A descrição e a interpretação das histórias de vida de três famílias de cafeicultores familiares numa postura etnográfica deixam apreender vasta gama de informações de seus modos de vida e de trabalho, deixa 
transparecer suas crenças, expõe seus valores, ainda que a riqueza infinita de uma experiência nunca possa ser descrita completamente.

Visto por dentro, o mundo rural se apresenta muito mais diverso e polissêmico, são muitos os mundos rurais no Brasil, assim como os sentidos que lhes emprestam. Uma visão já bem documentada é que o trabalho assalariado no campo permite à maioria dos trabalhadores rurais mobilizarem-se ao nível da mera sobrevivência. Nos casos em estudo, constatou-se a melhoria das condições sociais e econômicas de trabalhadores do café, que, no dizer deles, foi obtida graças a muito esforço e a determinado modo de vida. Devem ser minorias, mas expõem uma possibilidade.

A produção de café na região do estudo combina um aparente paradoxo: produtores familiares com fortes traços de tradição na organização familiar, na relação com a propriedade e com a terra têm uma produção principal modernizada destinada e integrada aos mercados interno e externo. Isso faz conviver modos de vida tradicionais com práticas produtivas altamente integradas ao consumo e com outras mais integradas à natureza e sem destinação comercial, com o fim de sobrevivência da própria família. Pode-se afirmar com segurança que não existem nem tipos ideais nem tipos puros de sujeitos rurais. Procurar por eles pode ser uma abstração inútil.

A família, a terra e o trabalho têm forte significado na vida desses produtores, os quais vivenciam e valorizam a família estendida, sob uma liderança forte (mas democrática) e aglutinadora, orientando-se por uma ética do esforço e do trabalho, na sua maior parte coletivo, visando à sobrevivência do grupo, sem se preocuparem exclusivamente com o mercado. Para eles, a terra representa mais que a propriedade, significa um modo de vida que deve ser transferido à geração que se segue. Vida afetiva e trabalho são vivenciados muito misturados por esses agricultores. Muitas vezes foi possível ouvir que o trabalho e o lazer se misturam: os espaços em que se movem, em grande parte, são os da natureza.

Com apoio em Bourdieu (2002) e Halbwachs (2004), afirma-se que não houve a intenção de tratar das classes sociais de produtores familiares, mas, em vez disso, tentouse descrever e interpretar quadros sociais da memória e da vida desses sujeitos para darIhes visibilidade e testemunho de que eles existem. E também não se ilusionou entender $\mathrm{e}$ narrar de forma completa e linear a vida de pessoas que lidam intensamente com a terra, sem vazios e lapsos, porque estes as constituem. 


\section{Referências}

ALMEIDA, R. A. Identidade, distinção e territorialização: O processo de (re)criação camponesa no Mato Grosso do Sul. 2003. 391f. Tese (Doutorado em Geografia) Universidade Estadual Paulista, Presidente Prudente, 2003.

BOURDIEU, P. A ilusão biográfica. In: FERREIRA, M. M.; AMADO, J. (Org.). Usos e abusos da história oral. Rio de Janeiro: FGV, 2002.

CÂNDIDO, A. Os parceiros do Rio Bonito. Rio de Janeiro: Ouro sobre Azul, 2010.

CARNEIRO, M. J. Herança e gênero entre agricultores familiares. Revista Estudos Feministas, Florianópolis, v. 9, n. 2, p. 22-55, jun./dez. 2001.

D'AQUINO, T. A casa, os sítios e as agrovilas: uma poética do tempo e do espaço no assentamento de trabalhadores rurais das Terras de Promissão-SP. In: ENCONTRO NACIONAL DE ESTUDOS RURAIS, 1996, São Paulo. Anais.... São Paulo, 1996.

FARIA, S. C. História da família e da demografia histórica. In: CARDOSO, C. F.; VAINFAS, R. (Org.). Domínios da história: ensaios de teoria e metodologia. Rio de Janeiro: Campos, 1997.

FERREIRA, A. B. H. Novo dicionário da língua portuguesa. 2. ed. Rio de Janeiro: Nova Fronteira, 1986.

GEERTZ, C. A interpretação das culturas. Rio de Janeiro: LTC, 2008.

GRAZIANO DA SILVA, J. A modernização dolorosa: estrutura agrária, fronteira agrícola e trabalhadores rurais no Brasil. Rio de Janeiro: Zahar, 1982.

GUANZIROLI, C. et al. Agricultura familiar e reforma agrária no século XXI. Rio de Janeiro: Garamount, 2009.

HALBWACHS, M. A memória coletiva. São Paulo: Centauro, 2004.

IBGE. Censo agropecuário 2006. Rio de Janeiro, 2009. Disponível em: <http://www.ibge.gov.br/home/estatística/economia/agropecuária/censoagro/Brasil censoagro2006.pdf>. Acesso em: 15 maio 2015.

MAGNANI, J. G. C. De perto e de dentro: notas para uma etnografia urbana de perto e de dentro: notas para uma etnografia urbana. Revista Brasileira de Ciências Sociais, São Paulo, v. 17, n. 49, p. 11-29, jun. 2002.

MARTIN, A. M. Terra, trabalho e família: considerações sobre a (re)criação do campesinato brasileiro nos movimentos sociais rurais. Revista História em Reflexão, Dourados, v. 2, n. 4, jul./dez. 2008.

MARX, K. Maquinaria e trabalho vivo (os efeitos da mecanização sobre o trabalhador). Crítica Marxista, São Paulo, v. 1, n. 1, p. 103-110, 1994. 
OLIVEIRA, S. S.; ZANINI, M. C. C. O trabalho como "categoria étnica": um estudo comparativo da ascensão social de imigrantes italianos e seus descendentes no rio grande do sul (1875-1975). Revista Interdisciplinar da Mobilidade Humana-REMHU, Brasília, Ano XVII, n. 33, p. 175-196, jul./dez. 2009.

REVEL, J. (Org.). Jogos de escala: a experiência da microanálise. Rio de Janeiro: FGV, 1998.

SAHLINS, M. O pessimismo sentimental e a experiência etnográfica: por que a cultura não é um objeto em via de extinção. Mana - Estudos de Antropologia Social, Rio de Janeiro, v. 3, n. 1, 1997.

SAMARA, E. M. Patriarcalismo, família e poder na sociedade brasileira (séculos XVI-XIX). Revista Brasileira de História, São Paulo, v. 11, n. 22, mar./ago. 1991.

SILVA, M. B. N. História da família no Brasil Colonial. Rio de Janeiro: Nova Fronteira, 1998.

SOUZA, C. A. S. A colônia vazia: trabalhadores sem trabalho e sem morada na lavoura de café do Sul de Minas Gerais. 2012. 117f. Dissertação (Mestrado em Política Social) Universidade Federal Fluminense, Niterói, 2012.

STOLCKE, V. Cafeicultura. Homens, mulheres e capital (1850-1980). São Paulo: Brasiliense, 1986.

THOMPSON, E. P. A miséria da teoria ou um planetário de erros. Rio de Janeiro: Zahar, 1981.

VEIGA, J. E. da. O desenvo/vimento agrícola: uma visão histórica. 2. ed. São Paulo: Edusp, 2007.

WOORTMANN, K. Com parente não se neguceia: o campesinato como ordem moral. Brasília: UNB, 1990. (Anuário Antropológico, 87). 